\title{
The correlation between the high-intensity zone on a T2-weighted MRI and positive outcomes of discography: a meta-analysis
}

\author{
Chunyang Fang, Wenbin Zhang, Liqiu Chen and Hongjie Li ${ }^{*}$
}

\begin{abstract}
Background: This meta-analysis aimed to assess the correlation between the high-intensity zone (HIZ) of a lumbar MRI and discography.

Methods: We conducted an electronic search of the PubMed, MEDLINE, Embase, and ScienceDirect databases from their respective inceptions to October 2016 using the following search terms: "low back pain," "discogenic low back pain," "HIZ or high-intensity zone," and "discography". Relevant journals and conference proceedings were manually searched. Two reviewers independently assessed the quality of the studies, extracted data from the included studies, and analyzed the data.

Results: Eleven studies were included. The results of the meta-analysis indicated that outstanding relativity and statistically significant correlations were observed between the HIZ and abnormal disc morphology $(\mathrm{OR}=47.79$; 95\% Cl: 17.07 to $133.77 ; P<0.00001), \mathrm{HIZ}$ and pain reproduction (OR=8.65, 95\% Cl: 6.01 to $15.23, P<0.00001)$, and $\mathrm{HIZ}$ and abnormal morphology pain reproduction (OR=11.74, 95\% Cl: 1.99 to $69.36, P=0.007)$.

Conclusions: The presence of an HIZ on a lumbar MRI T2-weighted image indicates abnormal disc morphology. There is a strong relationship between the HIZ and pain reproduction. The HIZ can be an effective index for prediction of discogenic low back pain.
\end{abstract}

Keywords: Low back pain, MRI, High-intensity zone, Discography, Meta-analysis

\section{Background}

Low back pain (LBP) is a common and devastating condition that causes disability or other severe complications [1]. In recent years, the incidence of LBP has gradually increased, and provocative discography is considered the gold standard for diagnosing LBP [2]. However, provocative discography is invasive and associated with complications, including neurological injury, infection, or contrast medium reaction [3].

In 1992, Aprill and Bogduk [4] first described a highintensity zone (HIZ) on magnetic resonance imaging (MRI) located in the posterior annulus fibrosus that was clearly separated from the nucleus pulposus. The appearance of an HIZ may indicate the rupture of intervertebral

\footnotetext{
* Correspondence: wzlihongjie@163.com

Department of Orthopedics, The First People's Hospital of Wenling, No. 190, Taiping Nan Road, Wenling, Zhejiang Province 317500, People's Republic of China
}

(c) The Author(s). 2017 Open Access This article is distributed under the terms of the Creative Commons Attribution 4.0 International License (http://creativecommons.org/licenses/by/4.0/, which permits unrestricted use, distribution, and reproduction in any medium, provided you give appropriate credit to the original author(s) and the source, provide a link to the Creative Commons license, and indicate if changes were made. The Creative Commons Public Domain Dedication waiver (http://creativecommons.org/publicdomain/zero/1.0/) applies to the data made available in this article, unless otherwise stated.

disc fibrous rings, which would cause nucleus pulposus herniation along the fissure. Leaked nucleus pulposus leads to an inflammatory reaction, which can result in the accumulation of granulation tissue with neovascularization as a reparative response. This phenomenon was observed on an MRI T2 as an HIZ and on discography as morphological abnormalities of the intervertebral disc. Several studies have confirmed that HIZ showed a notable histologic feature of the formation of vascularized granulation tissue and may be a specific indicator for an inflammatory reaction $[5,6]$. Aprill and Bogduk demonstrated that in morphologically abnormal discs, a significant correlation exists between an HIZ-positive disc and exact or similar pain reproduction on provocative discography.

The subsequent literature has reported consistent results $[7,8]$; however, several studies have shown a limited role of the HIZ in diagnosing LBP [9-11]. Consequently, the correlation between HIZ-positive discs and exact or 
similar pain reproduction on provocative discography remains controversial. Moreover, a few limitations, such as small sample size, inaccurate evaluations, and deficiencies in study design, could be observed in previous studies. Therefore, we conducted a large-scale meta-analysis to assess the correlation between an HIZ on lumbar MRI and provocative discography.

\section{Methods}

\section{Search strategy}

Based on the Cochrane Collaboration guidelines, we searched electronic databases including Cochrane Library, MEDLINE (1966-October 2016), PubMed (1966-October 2016), Embase (1980-October 2016), and ScienceDirect (1985-October 2016). In addition, the reference lists of all included studies were manually searched to identify trials that may have been missed in the initial search.

The search process was conducted as shown in Fig. 1. We used the keywords "low back pain," "discogenic low back pain," "HIZ or high-intensity zone," and "discography" in combination with the Boolean operators AND or OR. This study is a meta-analysis, which does not require either an ethics committee or institutional review board to approve the study.

\section{Inclusion criteria}

This review was conducted in accordance with guidelines described in the Cochrane handbook for systematic review and meta-analysis of interventions [12] and met the criteria of the Meta-analysis of Observational Studies in Epidemiology (MOOSE) [13].

Two review authors screened the titles and abstracts of all studies identified by the search strategy. Then, we retrieved the studies for full-text review and re-evaluated the articles according to the following inclusion criteria: (1) LBP assessed by MRI and discography and (2) exploration of HIZs on MRI and morphologically abnormal discs or similar pain reproduction on provocative discography. There were no restrictions on the patients' gender and age or time of publication. Disagreements were resolved by consensus.

\section{Quality assessment}

The methodological quality of the included studies was assessed by two independent reviewers according to the Strengthening the Reporting of Observational Studies in Epidemiology Statement (STROBE) [14]. The methodological quality of the studies was classified into three levels: A: more than $80 \%$ conformation to the STROBE

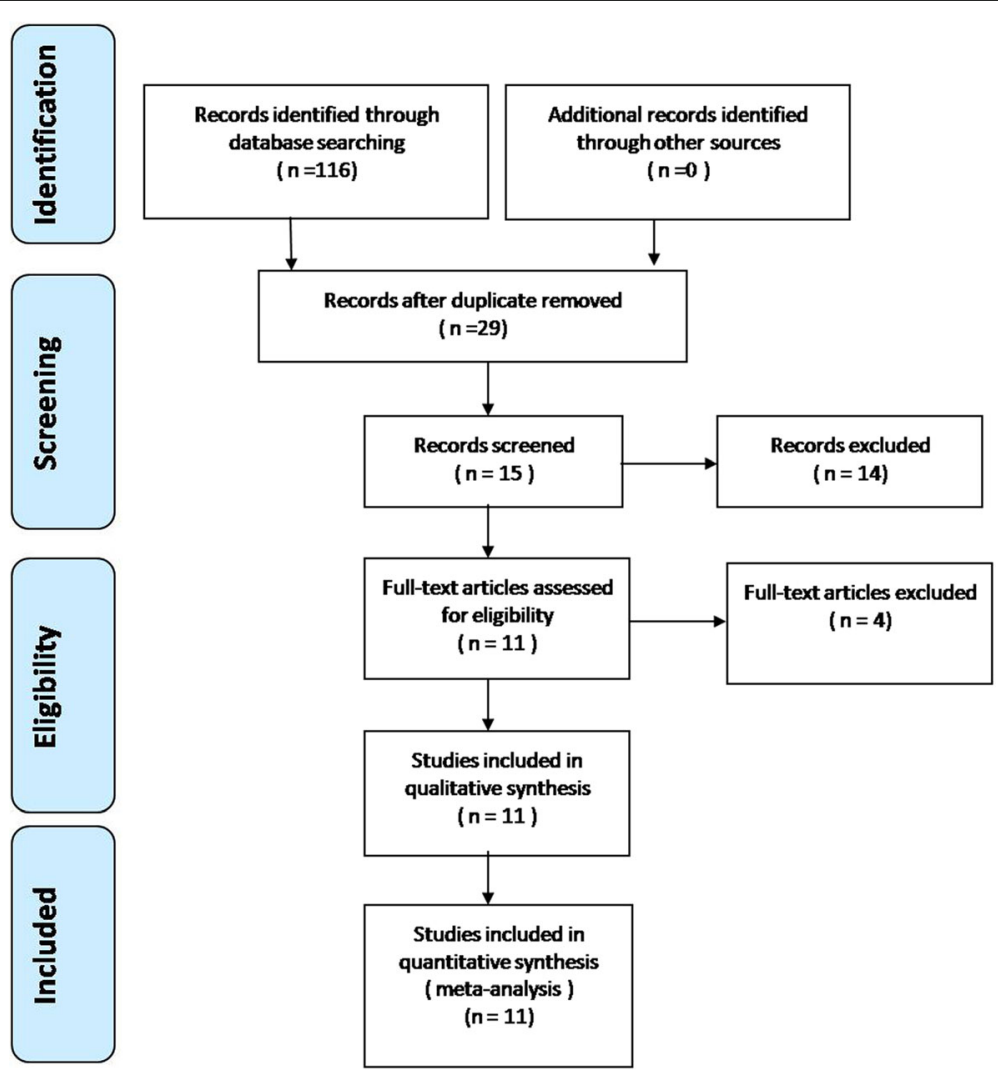

Fig. 1 Flowchart of the study selection process 
Table 1 Cohort characteristics

\begin{tabular}{|c|c|c|c|c|c|c|}
\hline Author & Study design & Magnetic field intensity & $\begin{array}{l}\text { Was discography } \\
\text { method described? }\end{array}$ & $\begin{array}{l}\text { Did the observer of MRI and } \\
\text { discography know each other? }\end{array}$ & $\begin{array}{l}\text { Is the statistical } \\
\text { method correct? }\end{array}$ & $\begin{array}{l}\text { Methodologic } \\
\text { quality }\end{array}$ \\
\hline Aprill 1992 & CS & $0.6 \mathrm{~T}$ & Yes & No & Yes & A \\
\hline Schellhas 1996 & RA & $1.5 \mathrm{~T}$ & Yes & No & Yes & A \\
\hline Ricketson 1996 & $\mathrm{CCT}$ & Not stated & Yes & No & Yes & $B$ \\
\hline Saifuddin 1998 & RA & $0.5-1.5 \mathrm{~T}$ & Yes & No & Yes & A \\
\hline Ito 1998 & $\mathrm{CCT}$ & $1.5 \mathrm{~T}$ & Yes & No & Yes & A \\
\hline Smith 1998 & RS & $1.5 \mathrm{~T}$ & Yes & No & Yes & A \\
\hline Lam 2000 & RS & $1.5 \mathrm{~T}$ & Yes & No & Yes & A \\
\hline Carrage 2000 & RA & Not stated & Yes & No & Yes & B \\
\hline Lim 2005 & $\mathrm{CCT}$ & $1.5 \mathrm{~T}$ & Yes & No & Yes & A \\
\hline Peng 2006 & $\mathrm{CCT}$ & $1.5 \mathrm{~T}$ & Yes & No & Yes & A \\
\hline Chen 2011 & $\mathrm{CCT}$ & $1.5 \mathrm{~T}$ & Yes & No & Yes & A \\
\hline
\end{tabular}

CS cohort study, RA retrospective analysis, CCT case-control study

standard; B: between 50 and $80 \%$ conformation to the STROBE standard; and C: less than 50\% conformation to the STROBE standard. Any disagreements were resolved by either consensus or consultation with a third reviewer.

\section{Data extraction}

Statistical analysis was performed using Review Manager 5.2 software (The Cochrane Collaboration, Oxford, United Kingdom), and a $P$ value $<0.05$ was considered statistically significant. For each eligible study, we calculated the odds ratios (OR) for dichotomous variables with $95 \%$ confidence intervals (CI). If outcomes were measured in the same way between studies, we calculated the mean differences (MD) and 95\% CI for continuous variables. Heterogeneity of the mean differences across the studies was assessed using the chi-squared test and $I^{2}$ statistic. If the results were significant $(P<0.1$ or $I^{2}>50 \%$, a random effects model was used to estimate the overall effect sizes, and a sensitivity analysis was performed to investigate the potential sources of heterogeneity. Otherwise, a fixed effects model was adopted. Moreover, publication bias among the studies was assessed by funnel plots.

\section{Results}

\section{Literature search}

The study selection process is shown in Fig. 1. We identified a total of 116 articles with our search strategy. After removing duplicates, scanning titles and abstracts and reading the full text, we identified 11 studies that were eligible based on our inclusion criteria $[4,5,9,15-22]$.

\section{Study characteristics and quality assessment}

All included trials involved lumbar discs and were published in English. The detailed characteristics of the studies are displayed in Table 1 . Nine of included studies were considered A level, and two of included studies were considered B level $[15,18]$.

\section{Outcomes of the meta-analysis \\ The relationship between HIZ and morphology in provocative discography}

The Dallas discogram scale [23] was used to evaluate the morphology based on provocative discography. Five included studies reported the relationship between HIZ and morphology based on provocative discography. No significant heterogeneity was found; therefore, the

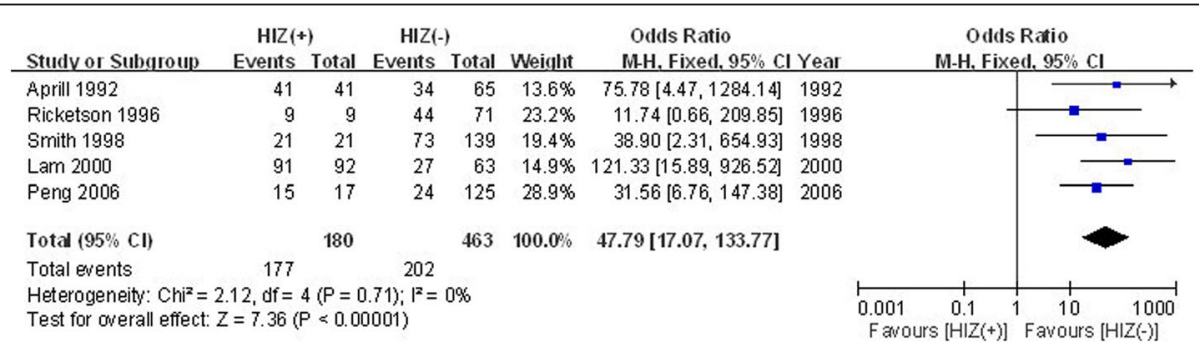

Fig. 2 Forest plot diagram showing the relationship between the HIZ and morphology based on provocative discography 


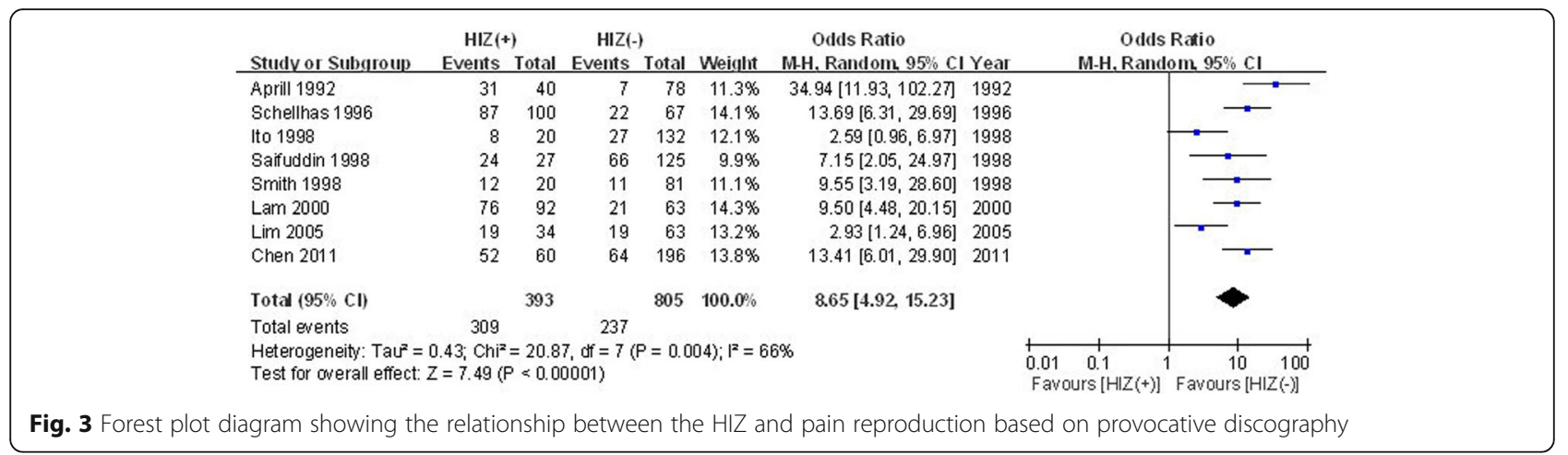

fixed effects model was applied $\left(\chi^{2}=2.12, d f=4, I^{2}=0\right.$, $P=0.71$ ). In the pooled analyses, there was a significant difference in morphologically abnormal discs (OR $=47.79 ; \quad 95 \% \quad \mathrm{CI}: 17.07$ to $133.77 ; \quad P<0.00001)$ between the HIZ-positive disc group and the HIZnegative disc group (Fig. 2).

\section{The relationship between the HIZ and pain reproduction based on provocative discography}

The relationship between the HIZ and pain reproduction based on provocative discography was shown in eight studies. Significant heterogeneity was found; thus, the random effects model was applied $\left(\chi^{2}=20.87, d f=7\right.$, $\left.I^{2}=66 \%, P=0.004\right)$. There were significant differences between the two groups $(\mathrm{OR}=8.65,95 \% \mathrm{CI}$ : 6.01 to 15.23, $P<0.00001$; Fig. 3).

\section{The relationship between the HIZ and pain reproduction of discs with abnormal morphology}

The relationship between the HIZ and pain reproduction of discs with abnormal morphology was described in four studies. Significant heterogeneity was found; thus, the random effects model was applied $\left(\chi^{2}=16.68, d f=3\right.$, $\left.I^{2}=82 \%, \quad P=0.0008\right)$. Pain reproduction of discs with abnormal morphology in the HIZ-positive disc group was significantly higher than that in the HIZ-negative disc group (OR $=11.74,95 \% \mathrm{CI}$ : 1.99 to $69.36, P=0.007$; Fig. 4 ).

\section{Discussion}

To our knowledge, this is the first meta-analysis to compare the HIZ with other metrics of LBP, which can help us obtain a more precise assessment of this phenomenon. The most important finding of the present study was that the HIZ on a lumbar MRI T2-weighted image was associated with abnormal disc morphology in the discography. In addition, there was a significant relationship between the HIZ and pain reproduction. The findings of the present study have important implications as they indicate that HIZ is a highly effective parameter in determining the intensity of discogenic LBP.

In 1992, Aprill and Bogduk first proposed that the HIZ can be a valuable indicator of a ruptured lumbar disc leading to LBP [4]. The appearance of an HIZ may indicate the rupture of intervertebral disc fibrous rings, which would cause nucleus pulposus herniation along the fissure. Leaked nucleus pulposus results in an inflammatory reaction, which can lead to accumulation of granulation tissue with neovascularization as a reparative response. This phenomenon was observed on an MRI T2 as an HIZ and on discography as morphological abnormalities of the intervertebral disc.

Trauma has been suggested as one of the causes of intervertebral disc disruption (IDD) [5]. Annular tear could possibly originate from trauma because of the structurally weak posterior part of annulus fibrosus [24]. However, Park

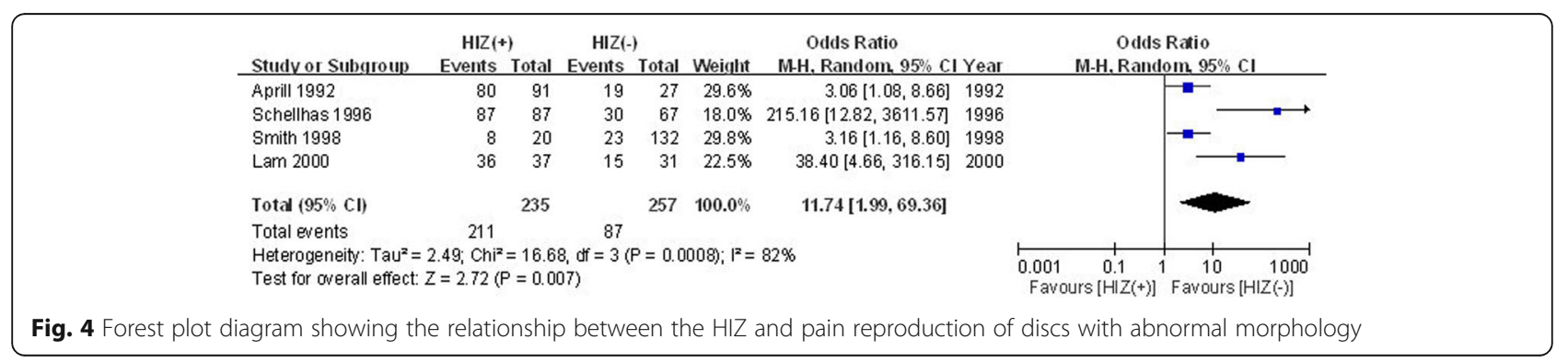


et al. concluded that the presence of HIZs on MR images showed a very weak correlation to trauma [25].

Several studies have investigated the clear association between the HIZ and provocative discography. The published literature has shown that the incidence of HIZ in patients with LBP is $25-50 \%[16,20]$. Schellhas et al. [20] reported that 87 of the 100 investigated HIZ discs were concordantly painful at the time of discography. Ito et al. [16] assessed the MRIs of 39 patients with LBP, including 101 discs, and found that $60 \%$ of the HIZpositive discs $(12 / 20)$ were concordantly painful at the time of discography, whereas $11 \%$ of the HIZ-negative discs $(11 / 81)$ were concordantly painful at the time of discography. Lam et al. [9] concluded that there was a significant correlation between the HIZ and either exact or similar pain reproduction in morphologically abnormal discs. Similar findings were demonstrated in other studies $[4,26]$.

In contrast, a previous study by Ricketson et al. [18] suggested that the HIZ was not related to the annular disruption in discography. Lei et al. [27] reported that the sensitivity and specificity of the HIZ were 27 and $87 \%$, respectively. Saifuddin et al. [19] confirmed that the HIZ is a marker of a painful posterior annular tear, but the usefulness of this parameter is limited by its low sensitivity (26.7\%). However, all of the abovementioned studies had relatively small sample sizes and were limited by insufficient statistical power. Thus, the exact association was still unclear.

In the present study, 11 studies of high methodological quality were included in this meta-analysis, and all of them met the MOOSE and STROBE requirements. In 2016, Jha et al. [3] performed a review of the HIZ for discogenic LBP. However, they did not extract data for further quantitative analysis. Thus, we conducted the present meta-analysis including all published studies to precisely estimate the relationship between the HIZ and provocative discography.

There were several potential limitations that should be noted. (1) The sample sizes of the included studies were relatively small; (2) the methodologies of the included studies have their own limitations; and (3) a subgroup analysis was not performed because we were unaware of any sources of heterogeneity due to limited number of included studies.

\section{Conclusions}

In conclusion, this meta-analysis showed that the presence of an HIZ on a lumbar MRI T2-weighted image indicates abnormal disc morphology. There is a strong relationship between the HIZ and pain reproduction. Finally, the HIZ can be an effective parameter to determine the contribution of the disc in LBP.

\section{Abbreviations}

Cl: Confidence intervals; HIZ: High-intensity zone; IDD: Intervertebral disc disruption; LBP: Low back pain; MD: Mean differences; MOOSE: Meta-analysis of Observational Studies in Epidemiology; MRI: Magnetic resonance imaging; OR: Odds ratios; STROBE: Strengthening the Reporting of Observational Studies in Epidemiology Statement

\section{Acknowledgements}

We thank the authors of the included studies.

Funding

None.

\section{Availability of data and materials}

As this paper is a meta-analysis, there are no patient data sets. The search strategy for the study selection, which support the conclusion of the meta-analysis, is provided.

\section{Authors' contributions}

CFY, WBZ, and HJL conceived the design of the study. CFY, LQC, and HJL performed and collected the data and contributed to the design of the study. CFY, WBZ, and HJL prepared and revised the manuscript. All authors read and approved the final content of the manuscript.

\section{Authors' information}

The author information can be found in the title page.

\section{Competing interests}

The authors declare that they have no competing interests.

Consent for publication

Not applicable.

Ethics approval and consent to participate

Not applicable, this meta-analysis does not involve research on humans.

Received: 16 November 2016 Accepted: 21 January 2017

Published online: 08 February 2017

References

1. Maher C, Underwood M, Buchbinder R. Non-specific low back pain. Lancet. 2016. http://www.thelancet.com/journals/lancet/article/PIIS01406736(16)30970-9/abstract. doi:10.1016/50140-6736(16)30970-9. [Epub ahead of print].

2. Koes BW. Evidence-based management of acute low back pain. Lancet. 2007;370(9599):1595-6.

3. Jha SC, Higashino K, Sakai T, Takata Y, Abe M, Yamashita K, Morimoto M, Fukuta S, Nagamachi A, Sairyo K. Clinical significance of high-intensity zone for discogenic low back pain: a review. J Med Invest. 2016;63(1-2):1-7.

4. Aprill C, Bogduk N. High-intensity zone: a diagnostic sign of painful lumbar disc on magnetic resonance imaging. Br J Radiol. 1992;65(773):361-9.

5. Peng B, Hou S, Wu W, Zhang C, Yang Y. The pathogenesis and clinical significance of a high-intensity zone (HIZ) of lumbar intervertebral disc on MR imaging in the patient with discogenic low back pain. Eur Spine J. 2006;15(5):583-7.

6. Dongfeng R, Hou S, Wu W, Wang H, Shang W, Tang J, Li Z, Lei G. The expression of tumor necrosis factor-alpha and CD68 in high-intensity zone of lumbar intervertebral disc on magnetic resonance image in the patients with low back pain. Spine (Phila Pa 1976). 2011:36(6):E429-433.

7. Endean A, Palmer KT, Coggon D. Potential of magnetic resonance imaging findings to refine case definition for mechanical low back pain in epidemiological studies: a systematic review. Spine (Phila Pa 1976). 2011;36(2):160-9.

8. Kang $\mathrm{CH}$, Kim YH, Lee SH, Derby R, Kim JH, Chung KB, Sung DJ, Can magnetic resonance imaging accurately predict concordant pain provocation during provocative disc injection? Skeletal Radiol. 2009:38(9):877-85.

9. Lam KS, Carlin D, Mulholland RC. Lumbar disc high-intensity zone: the value and significance of provocative discography in the determination of the discogenic pain source. Eur Spine J. 2000;9(1):36-41.

10. Rankine JJ, Gill KP, Hutchinson CE, Ross ER, Williamson JB. The clinical significance of the high-intensity zone on lumbar spine magnetic 
resonance imaging. Spine (Phila Pa 1976). 1999;24(18):1913-9. discussion 1920.

11. Buirski G, Silberstein M. The symptomatic lumbar disc in patients with low-back pain. Magnetic resonance imaging appearances in both a symptomatic and control population. Spine (Phila Pa 1976). 1993;18(13):1808-11.

12. Handoll HH, Gillespie WJ, Gillespie LD, Madhok R. The Cochrane Collaboration: a leading role in producing reliable evidence to inform healthcare decisions in musculoskeletal trauma and disorders. Indian $\rfloor$ Orthop. 2008;42(3):247-51.

13. Stroup DF, Berlin JA, Morton SC, Olkin I, Williamson GD, Rennie D, Moher D, Becker BJ, Sipe TA, Thacker SB. Meta-analysis of observational studies in epidemiology: a proposal for reporting. Meta-analysis Of Observational Studies in Epidemiology (MOOSE) group. JAMA. 2000;283(15):2008-12.

14. von Elm E, Altman DG, Egger M, Pocock SJ, Gotzsche PC, Vandenbroucke JP. The Strengthening the Reporting of Observational Studies in Epidemiology (STROBE) Statement: guidelines for reporting observational studies. Int J Surg. 2014;12(12):1495-9.

15. Carragee EJ, Paragioudakis SJ, Khurana S. 2000 Volvo Award winner in clinical studies: lumbar high-intensity zone and discography in subjects without low back problems. Spine (Phila Pa 1976). 2000;25(23):2987-92.

16. Ito M, Incorvaia KM, Yu SF, Fredrickson BE, Yuan HA, Rosenbaum AE. Predictive signs of discogenic lumbar pain on magnetic resonance imaging with discography correlation. Spine (Phila Pa 1976). 1998;23(11):1252-8. discussion 1259-1260.

17. Lim CH, Jee WH, Son BC, Kim DH, Ha KY, Park CK. Discogenic lumbar pain: association with MR imaging and $\mathrm{CT}$ discography. Eur J Radiol. 2005;54(3):431-7.

18. Ricketson R, Simmons JW, Hauser BO. The prolapsed intervertebral disc. The high-intensity zone with discography correlation. Spine (Phila Pa 1976). 1996;21(23):2758-62

19. Saifuddin A, Braithwaite I, White J, Taylor BA, Renton P. The value of lumbar spine magnetic resonance imaging in the demonstration of anular tears. Spine (Phila Pa 1976). 1998;23(4):453-7.

20. Schellhas KP, Pollei SR, Gundry CR, Heithoff KB. Lumbar disc high-intensity zone. Correlation of magnetic resonance imaging and discography. Spine (Phila Pa 1976). 1996;21 (1):79-86.

21. Smith BM, Hurwitz EL, Solsberg D, Rubinstein D, Corenman DS, Dwyer AP, Kleiner J. Interobserver reliability of detecting lumbar intervertebral disc high-intensity zone on magnetic resonance imaging and association of high-intensity zone with pain and anular disruption. Spine (Phila Pa 1976). 1998;23(19):2074-80.

22. Chen JY, Ding Y, Lv RY, Liu QY, Huang JB, Yang ZH, Liu SL. Correlation between MR imaging and discography with provocative concordant pain in patients with low back pain. Clin J Pain. 2011;27(2):125-30.

23. Sachs BL, Vanharanta H, Spivey MA, Guyer RD, Videman T, Rashbaum RF, Johnson RG, Hochschuler SH, Mooney V. Dallas discogram description. A new classification of CT/discography in low-back disorders. Spine (Phila Pa 1976). 1987:12(3):287-94.

24. Tsuji H, Hirano N, Ohshima H, Ishihara H, Terahata N, Motoe T. Structural variation of the anterior and posterior anulus fibrosus in the development of human lumbar intervertebral disc. A risk factor for intervertebral disc rupture. Spine (Phila Pa 1976). 1993;18(2):204-10.

25. Park KW, Song KS, Chung JY, Choi JM, Lee JH, Lee CK, Chang BS. High-intensity zone on L-spine MRI: clinical relevance and association with trauma history. Asian Spine J. 2007;1(1):38-42.

26. Horton WC, Daftari TK. Which disc as visualized by magnetic resonance imaging is actually a source of pain? A correlation between magnetic resonance imaging and discography. Spine (Phila Pa 1976). 1992;17(6 Suppl):S164-171.

27. Lei D, Rege A, Koti M, Smith FW, Wardlaw D. Painful disc lesion: can modern biplanar magnetic resonance imaging replace discography? I Spinal Disord Tech. 2008;21(6):430-5.

\section{Submit your next manuscript to BioMed Central and we will help you at every step:}

- We accept pre-submission inquiries

- Our selector tool helps you to find the most relevant journal

- We provide round the clock customer support

- Convenient online submission

- Thorough peer review

- Inclusion in PubMed and all major indexing services

- Maximum visibility for your research

Submit your manuscript at www.biomedcentral.com/submit
Biomed Central 